\title{
O Whatsapp no apoio à resolução de problema de matrizes: um produto educacional na EJA
}

\author{
Whatsapp in support of problem solving of an educational product in \\ EJA
}

\author{
Michel Silva dos Reis ${ }^{1}$ \\ Osvaldo dos Santos Barros²
}

\section{Resumo}

Apresentamos o Produto Educacional, fruto de uma prática docente que culminou em uma dissertação de mestrado profissional. A pesquisa trata do método da Resolução de Problemas e do ensino e aprendizagem da Matemática, trabalhando o conteúdo de Matrizes no Ensino Médio, em turmas da Educação de Jovens e Adultos - EJA. Como plano de apoio didático temos a utilização do aplicativo Whatsapp sendo ferramenta pedagógica nas aulas de matemática. O objetivo desse artigo é apresentar um relato de experiência, fruto de investigação da prática docente, quando discutimos sobre as contribuição das novas tecnologias e redes sociais, aos processos de raciocínio, na resolução de problemas dos conteúdos de matrizes trabalhados em sala de aula, realizada no segundo bimestre de 2016, em turmas da EJA. Apresentamos, também, as análises dos comentários feitos pelos alunos no ambiente virtual e as anotações durante as aulas presenciais. Os relatos das atividades e dinâmicas trabalhadas em sala de aula e no ambiente virtual visam auxiliar o professor quando do desenvolvimento dessa proposição metodológica em sala de aula.

Palavras-chave: Produto Educacional. Whatsapp. Resolução de Problemas. Matrizes. EJA.

\footnotetext{
1 Mestre em docência em Educação em Ciências e Matemáticas (IEMCI/UFPA) - mestrado profissional. Professor da Secretaria Estadual de Educação de Belém - SEDUC. E-mail: michel07.silva@hotmail.com

2 Doutor em educação (UFRN). Professor de ensino superior na UFPA, na pós-graduação e no Programa de Pós-Graduação em Docência em Educação em Ciências e Matemáticas - Mestrado Profissional. E-mail: o.barros@yahoo.com.br
} 


\section{Abstract}

We present the Educational Product, the result of a teaching practice that culminated in a master's degree dissertation. The research deals with the Problem Solving method and the teaching and learning of Mathematics, working the content of Matrices in High School, in classes of Education of Young and Adults - EJA. As a didactic support plan we use the Whatsapp application as a pedagogical tool in math classes. The objective of this article is to present an experience report, the result of research on teaching practice, when we discuss the contribution of new technologies and social networks, to the reasoning processes, in the resolution of problems of the contents of matrices worked in the classroom, carried out in the second two-month period of 2016, in classes of the EJA. We also present the analyzes of the comments made by the students in the virtual environment and the notes during the classes. The reports of activities and dynamics worked in the classroom and in the virtual environment, aim to assist the teacher when developing this methodological proposition in the classroom.

Keywords: Educational Product. Troubleshooting. Whatsapp platform. Matrices.

\section{Introdução}

No Mestrado Acadêmico, de modo geral, o produto fim da pesquisa, além da dissertação é um recurso didático voltado à prática docente, o que aqui denominados Produto Educacional. Nesse artigo apresentamos o resultado das nossas investigações em sala de aula, materializado em um produto do mestrado profissional, no formato de um livro de orientações ao professor, visando descrever, como relato de experiência, o processo de elaboração e prática docente da proposta de utilização de recursos tecnológicos nas aulas de matemática.

Essa proposta insere-se na área de Educação Matemática, tendo como foco o ensino de Matrizes a partir da resolução de problemas na Educação de Jovens e Adultos, utilizando como meio de diálogos entre o professor e os alunos, o aplicativo Whatsapp ${ }^{3}$. As atividades foram realizadas com 25 alunos da $2^{\circ}$ Etapa

3 Aplicativo multiplataforma de mensagens instantâneas e chamadas de voz e vídeo para smartphones. Além de mensagens de texto, os usuários podem enviar imagens, vídeos e documentos em PDF e fazer ligações grátis por meio de uma conexão com a internet. Para mais informações sobre o aplicativo ou guia sobre sua utilização consultar página: https://www.whatsapp.com/faq/pt_br/general/21073018. 
do Ensino Médio de uma escola da rede pública de ensino do estado do Pará, na periferia de Belém. Iniciamos, então, pelas indagações que levaram a realização da pesquisa; a apresentação do produto educacional; a fundamentação teórica; os aspectos metodológicos da ação e a descrição de algumas atividades realizadas.

Os alunos da EJA ao retornarem para escola depois de muitos anos, com idade avançada e com uma grande carga de experiência e vivência, necessitavam de uma motivação diferenciada. Um dos elementos encontrado foi o aplicativo Whatsapp, pois era algo do cotidiano deles, era o ambiente que estavam acostumados. E, ainda nesta busca por motivação, resolveu-se utilizar durante as aulas de matemática o método de Resolução de Problemas descrito pelo autor George Polya, em seu livro intitulado: "A Arte de Resolver Problemas", para aguçar a curiosidade dos alunos, o prazer pela descoberta e da experimentação. Para tanto, o professor ao orientar o aluno:

Deve auxiliá-lo discretamente, sem dar na vista. As sugestões devem ser simples e naturais, porque do contrário elas não poderiam ser discretas. As sugestões devem ser genéricas, aplicáveis não apenas ao problema presente, mas também a problemas de todos os tipos, pois só assim elas poderão desenvolver a capacidade do estudante e não somente uma técnica específica (POLYA, 2006, p.01 e p.17).

O conteúdo de Matrizes do Ensino Médio foi utilizado na pesquisa pelo fato de que os próprios alunos a elegeram ao verem uma aula em outra turma, além de fazer parte do conteúdo do programa escolar do ensino médio. Logo nas primeiras aulas, os alunos da EJA, demonstraram interesse e relevância durante as discussões, neste sentido, foi decido ali o objeto de estudo.

No envolto destas ideias foi que surgiu a pergunta de pesquisa: "Como utilizar o Whatsapp para promover autonomia da aprendizagem, construção do conceito e a interação do aluno com o conceito matemático a partir da mídia?". Para responder essa pergunta, lançamos como objetivo geral da pesquisa: 
discutir o estudo de Matrizes a partir da Resolução de Problemas, utilizando como meio o Whatsapp.

A organização dos grupos virtuais como ambiente pedagógico se deu ao percebermos que na plataforma Whatsapp, os alunos, também trabalhadores, teriam seu tempo de estudo ampliado em relação às aulas presenciais, a partir dos pequenos comentários por mensagens, além da possibilidade de postagem de fotografias. Os alunos teriam em mãos a revisão dos conteúdos, da aula presencial e o registro das conversas (comentários) e explicações do professor e dos seus colegas de classe. Os diálogos seriam assim, um poderoso aliado na resolução de problemas propostos em sala de aula.

O estudo de caso, como metodologia da pesquisa, foi escolhido primeiramente pelo enquadramento da questão de pesquisa proposta, já que segundo Yin (2015, p.xvi), O enquadramento das questões pode ser um dos elementos que influenciam diretamente na escolha dos métodos de pesquisa. Outro fato que levou a escolha de tal metodologia foi de que o estudo de caso (YIN,2015, p. 4, 5 e 36), contribui para o conhecimento de fenômenos grupais comum na Educação, focando no "caso" ao observar o comportamento de pequenos grupos e o desempenho escolar, trazendo um "caso de ensino".

Já possuíamos o intuito de conduzir uma pesquisa qualitativa na perspectiva de Creswell (2014, p. 52), para explorar o problema em questão, pela necessidade de estudar um grupo, para escutar vozes muito tempo silenciadas, ou seja, para compreender os contextos ou ambientes em que os participantes estavam inseridos.

Acreditamos que, como professores, devemos utilizar a tecnologia para a aprendizagem dos nossos alunos, demonstrando interesse naquilo que os alunos consideram interessante, fazendo com que o estudante busque conhecimento matemático com a interação via tecnologia: mensagens, vídeos, pesquisas, imagens, gráficos. Neste sentido o professor pode promover autonomia à aprendizagem dos alunos por meio da motivação com a interação por meio da mídia. 
Movido pelo desejo de contribuir no ensino e aprendizagem de matrizes para aqueles que compartilhem o desejo de aplicar esta pesquisa ou associar outro viés para tal prática, torna-se imprescindível à confecção de um produto desta pesquisa, sendo este um caderno de apoio para professores de matemática.

\section{Apresentação do Produto Educacional}

O produto educacional é um livro, recorte da dissertação de mestrado profissional, onde foi investigado a proposta de utilização do aplicativo Whatsapp como ambiente de diálogos e estudos complementares dos conceitos e dos conteúdos matemáticos, com alunos da segunda etapa do Ensino Médio da Educação de Jovens e Adultos - EJA, visando buscar aprendizagem na resolução de problemas.

Neste contexto apresentamos um relato de experiência, onde exercitamos a construção do conceito de Matriz, procuramos analisar os comentários dos alunos, fazendo uma organização no ambiente de estudo dos mesmos em dois ambientes de maneira alternada: o primeiro é a sala de aula, no qual trataremos do método de Polya (2006) para a resolução de problemas e o segundo, o ambiente virtual na plataforma Whatsapp, onde promovemos o diálogo entre os alunos no sentido exercitar os conceitos e propriedades das matrizes, denominamos esses espaços de ambiente misto. Além disso, traremos para análise os resultados de testes aplicados em sala de aula e outros materiais produzidos pelos alunos, com o intuito de discutir aspectos qualitativos de tais atividades.

No desenvolvimento do livro, procuramos trazer o modo como foi pensado e organizado a pesquisa, as questões objetivas, as questões subjetivas e uma atividade em grupo, quando os alunos apresentam resoluções de problemas. Objetivamos uma avaliação dinâmica na perspectiva de Brito (2010), no sentido de buscar o entendimento sobre "como" o aluno trabalha o conteúdo aprendido, 
ao contrário de avaliação estática, que tem como objetivo verificar "o que" e "quanto" o aluno aprendeu.

A utilização da internet como via de comunicação entre professor e aluno adulto torna-se interessante no momento em que os envolvidos possam trocar informações relevantes ao ensino da matemática, o aluno tem em mãos um poderoso meio de tirar suas dúvidas, pedir orientações e partilhar conhecimentos, realizando conferências em grupos virtuais no Whatsapp, enviando mensagens de texto ou de áudio, compartilhando ideias, angustias e socializando experiências em contato com o estudo de Matrizes.

Dessa maneira, o formato do produto educacional tem como objetivo apresentar ao professor de matemática um caderno de apoio para aqueles que queiram compartilhar dessa prática de ensino, utilizando o aplicativo Whatsapp para estudar as propriedades e aplicações das Matrizes, em suas aulas de matemática, utilizando o ambiente virtual para socialização dos conteúdos matemáticos envolvidos.

Neste sentido, a proposta da dissertação de mestrado foi materializada em um livro, pois o professor pode organizar suas atividades pedagógicas utilizando o método de Resolução de Problemas, traçando discussões entre os alunos para criarem e resolverem problemas em aulas de matemática. Enquanto ao tempo pedagógico, poderá ser mais bem aproveitado, já que com a utilização da plataforma virtual no aplicativo Whatsapp há uma ampliação da sala de aula, pois terá a oportunidade de dar continuidade às discussões sobre matemática, tirar dúvidas e propor novos problemas nos grupos virtuais, ou seja, ter a otimização do seu tempo pedagógico.

\section{Fundamentação teórica}

Ao tratar do uso de tecnologias digitais, onde o aluno encontra-se mergulhado culturalmente no contexto informatizado, que no caso seria o uso do 
Whatsapp, como primeiro autor, Pierre lévy com sua obra: "As tecnologias da Inteligência", pois este autor trata com maestria a relação entre o ser humano e a era informatizada, explorando o que o autor chama de "cibercultura" em seu livro "cyberculture", traz a discussão sobre o uso de elementos informatizados e seu papel no desenvolvimento intelectual do ser humano frente às novas tecnologias, pois se educar quer dizer, cada vez mais, aprender, transmitir saberes e produzir conhecimentos, dentro do ciberespaço temos tecnologias intelectuais que amplificam, exteriorizam e modificam numerosas funções cognitivas humanas como: memória, imaginação, percepção e raciocínios (LÉVY, 1999, p.157).

Lévy (2007, p.17) nos alerta que o número de mensagens em circulação nunca foi tão grande, mas temos muito poucas ferramentas para filtrar informações relevantes. Ao educador que se depara com estes tipos de diversidades culturais, o ensino qualitativo requer uma visão da necessidade de novas experiências tecnológicas educativas bem direcionadas, que tenham por base os componentes sociais e integradores para situar o professor dentro do espaço tecnológico vivenciado pela maioria de nossos jovens na escola.

O método da Resolução de Problemas se faz presente, nesta discussão sobre tecnologia, pelo fato de poder proporcionar ao aluno o despertar pelo interesse do objeto matemático estudado no decorrer de suas aulas. O professor de matemática pode direcionar nos ambientes virtuais momentos de discussões para que os alunos possam criar suas próprias estratégias e não esperar que o professor o faça.

Além de Polya (2006), pesquisas como de Schoenfeld (1985), Pozo (1998), Pais (2001), Smole e Diniz (2001), Onuchic e Allevato (2011), Dante (2003) e Mendes (2009), recomendam a abordagem dos conceitos de Matemática a partir da Resolução de Problemas, relacionado ao conhecimento do conteúdo anteriormente adquirido, de modo a permitir a troca de pontos de vista por meio do cálculo experimental. $\mathrm{O}$ aluno adquire conhecimento matemático com o auxílio discreto do professor, que indaga para sugestionar atitudes positivas, de modo 
que este adquira independência para realizar operações mentais sem a necessidade da presença de um instrutor.

É importante desenvolver a capacidade de raciocinar frente a uma determinada situação em vez de somente trabalhar técnicas de resolução, o professor deve propiciar momentos de diálogo para melhor entender os seus próprios alunos, visando atribuir repertórios matemáticos suficientes para o bom entendimento de vocabulários próprios da área de Matemática. Pois, o estudante deve refletir, analisar e adquirir experiência objetivando autonomia no seu modo de pensar ao realizar operações matemáticas mais complexas, relacionando com problemas mais simples ou correlatos. Pois, "é difícil imaginar um problema absolutamente novo, sem qualquer semelhança ou relação com qualquer outro que já haja sido resolvido; se um tal problema pudesse existir, ele seria insolúvel" (POLYA, 2006, p. 41).

O livro Álgebra II (1975) foi escolhido para compor a pesquisa por sua abordagem mais criteriosa a cerca do estudo de Matrizes. Além disso, foi o único livro encontrado que aborda inicialmente o conceito de matrizes envolvendo funções e par ordenado, o que facilitou aos alunos identificarem os elementos de uma matriz "m por n" ou um elemento "aij" sem confundir na representação da posição de linhas e colunas na matriz algébrica.

Um exemplo disso seria uma matriz de 10 linhas e 11 colunas, ou seja, uma matriz 10 por 11 ou simplesmente $10 \times 11$. A representação genérica da $1^{1}$ linha e $1^{\text {a }}$ coluna, representaríamos por $\mathbf{a}_{11}$. Logo, não há confusão da posição existente entre linhas e colunas e a representação foi direta.

Porém ao deparar-se com elementos que estão em posições de linhas e colunas maiores que 9 gera confusão na representação pois:10 $0^{\mathrm{a}}$ linha e $11^{\text {a }}$ coluna, representaríamos por a1011? Pois aqui não fica claro a posição linha e coluna do elemento da matriz algébrica.

Neste sentido, houve necessidade de uma definição esclarecedora sobre tal dúvida, o que foi resolvido na abordagem do livro "Álgebra II", que traz em sua definição os seguintes dizeres: "O número $a_{i j}$ é chamado imagem do par $(i, j)$ ". 
Logo para os exemplos anteriores teríamos: $a_{11}$ sendo imagem do par $(1,1)$. E para nosso dilema, teríamos: $10^{\underline{a}}$ linha e $11^{\underline{a}}$ coluna, representaríamos por $a_{(10,11)}$ sendo imagem do par $(10,11)$, não havendo confusão entre linha e coluna.

Dentro do contexto descrito, temos três bases para o desenvolvimento da pesquisa: o conceito matemático a ser trabalhado com os alunos: o conteúdo de Matrizes; o material didático informatizado virtual utilizado para dar apoio às aulas e gerar motivação nos alunos: o Whatsapp; e a teoria de aprendizagem que rege a aula presencial de matemática na sala de aula: A Resolução de Problemas.

\section{Aspectos Metodológicos da Ação}

Após realizado um contrato pedagógico com os envolvidos, propomos uma aula dividida em dois momentos: presencial e virtual.

\begin{tabular}{|c|c|}
\hline $\begin{array}{l}\text { (1) Aula Presencial: } \\
\text { - Realizada dentro do ambiente } \\
\text { de sala de aula; } \\
\text { - Intencionalidade de trabalhar } \\
\text { o conteúdo proposto; } \\
\text { - Tempo escola, presencial; } \\
\text { - Professor, quadro magnético, } \\
\text { aluno, característica de aula } \\
\text { formal; } \\
\text { - Resolução de Problemas; }\end{array}$ & $\begin{array}{l}\text { (2) Aula Virtual: } \\
\text { - Realizada dentro do ambiente } \\
\text { virtual; } \\
\text { - Intencionalidade de discutir } \\
\text { conceitos matemáticos; } \\
\text { - Tempo comunidade, aula à } \\
\text { distância; } \\
\text { - Professor, imagens, diálogo } \\
\text { por mensagens; }\end{array}$ \\
\hline
\end{tabular}

QUADRO 1: Aula mista.

FONTE: Próprio autor

No primeiro momento, em aula presencial, será considerado método heurístico (heurística moderna), que segundo Polya (2006, p.100), é a parte da filosofia que se dedica a inventar maneiras de resolver problemas, procurando compreender o processo solucionador desses problemas. Nesta ordem, temos os passos: (1) Compreensão do Problema: é preciso compreender o problema, ter uma leitura atenta; (2) Estabelecimento de um Plano: é necessário encontrar a 
conexão entre os dados e a incógnita. Caso necessário, procurar problemas correlatos, buscando em seu repertório algo que faça uma conexão para chegar a um plano para resolução; (3) Execução do Plano: Execute o plano traçado (ação). Verifique cada passo; e por último, (4) Retrospecto: Examinar a solução obtida, assim como correlacionar com outras soluções ou verificar se sua solução se adéqua a outro problema.

O segundo momento virtual, aula à distância, tem como objetivo, fazer com que os alunos da EJA trabalhem conversando no grupo virtual Whatsapp, pois assim como um trabalho ou um "dever de casa" que o professor propõe para os alunos levar em um dia da semana para entregar em outra, o ambiente virtual fora da sala de aula funcionará como um fórum de discussão, orientado pelo professor, com os alunos interagindo, trocando mensagens, enviando respostas, pesquisando, dialogando, ou seja, trocando informações entre si, procurando provocar autonomia nos mesmos.

Dentro do ambiente virtual, o objeto matemático em estudo, seu conceito é estruturado de forma que as informações sejam divididas em telas, o aluno no fórum de discussões deve olhar cada tela e analisar a informação contida, que sempre será algo objetivo e pontual, pois a plataforma do Whatsapp possui a característica de uma leitura imediata, sendo assim o professor deve postar imagens que caibam em uma tela de celular, seguido de textos curtos, para os alunos observarem a imagem, refletirem sobre o conceito matemático no estudo de matrizes que esta sendo envolvido, e assim responderem a mensagem. Neste sentido, trabalha-se o principio da síntese matemática em poucas palavras, telas ou em vídeos curtos.

Neste sentido, as atividades foram organizadas da seguinte forma: 4 aulas presenciais e 3 aulas a distância (virtual) no Whatsapp:

1. Atividade Presencial 1: Introdução ao Estudo de Matrizes.

2. Atividade Virtual 1: Representação de Matrizes.

3. Atividade Presencial 2: Representação Genérica de Matrizes.

4. Atividade Virtual 2: Elementos da Matriz Genérica. 
5. Atividade Presencial 3: Lei de Formação de Matrizes.

6. Atividade Virtual 3: Matrizes Especiais.

7. Atividade Presencial 4: Revisão e Operações com Matrizes.

Para exemplificar essa situação, traremos a seguir dos dois momentos da pesquisa, um presencial e outro virtual:

Primeiro Momento: Atividade Presencial: Matriz Genérica:

Neste encontro de sala de aula, discutimos a representação genérica de uma matriz, que segundo Paiva (2013, pag.95), seria: "A indicação por aij o elemento posicionado na linha i e na coluna j de uma matriz A". Assim teríamos:

$$
A_{m \times n}=\left(\begin{array}{ccccc}
a_{11} & a_{12} & a_{13} & \ldots & a_{1 n} \\
a_{21} & a_{22} & a_{23} & \ldots & a_{2 n} \\
a_{31} & a_{32} & a_{33} & \ldots & a_{3 n} \\
\vdots & \vdots & \vdots & \vdots & \vdots \\
a_{m 1} & a_{m 2} & a_{m 3} & \ldots & a_{m n}
\end{array}\right)
$$

Temos a apresentação dos elementos da matriz A com seu respectivo posicionamento de linha e coluna:

$$
\begin{aligned}
& \text { a11 - seria o elemento posicionado na } 1^{\text {a }} \text { linha e } 1^{\text {a }} \text { coluna da matriz A } \\
& a_{21} \text { - seria o elemento posicionado na } 2^{\underline{a}} \text { linha e } 1^{\text {a }} \text { coluna da matriz A }
\end{aligned}
$$

am1 - seria o elemento posicionado na linha " $m$ " e $1^{\text {a }}$ coluna da matriz A $a_{1 n}$ - seria o elemento posicionado na $1^{a}$ linha e coluna " $n$ " da matriz $A$ $a_{m n}$ - seria o elemento posicionado na linha "m" e coluna " $n$ " da matriz $A$

Temos que deixar bem definido aos alunos a numeração das linhas e das colunas, para que não haja equívocos na definição do posicionamento dos elementos, o que infelizmente o livro didático que os alunos possuíam, trata matriz genérica com dados muito resumidos, o que conduz o aluno a muitos 
questionamentos: "a primeira linha começa de cima ou de baixo?", "a coluna inicial é a da esquerda ou da direita?", "os elementos que aparecem dentro da matriz podem ser qualquer letra?", "isso funciona pra qualquer matriz?", "sempre o primeiro é $a_{11}$ ?".

Diante de tantos questionamentos, considerei melhor refazer nossa representação, para deixar claro o sentido e direção de linhas e colunas:

Por: $1^{\underline{a}}$ linha, $2^{\text {a }}$ linha, $3^{\text {a }}$ linha, ... até "m" linha, sempre nessa ordem, entendem-se:



Sempre nessa ordem, por: $1^{\underline{a}}$ coluna, $2^{\underline{a}}$ coluna e $3^{\underline{a}}$ coluna, $\ldots$, até "n" coluna entendemos:

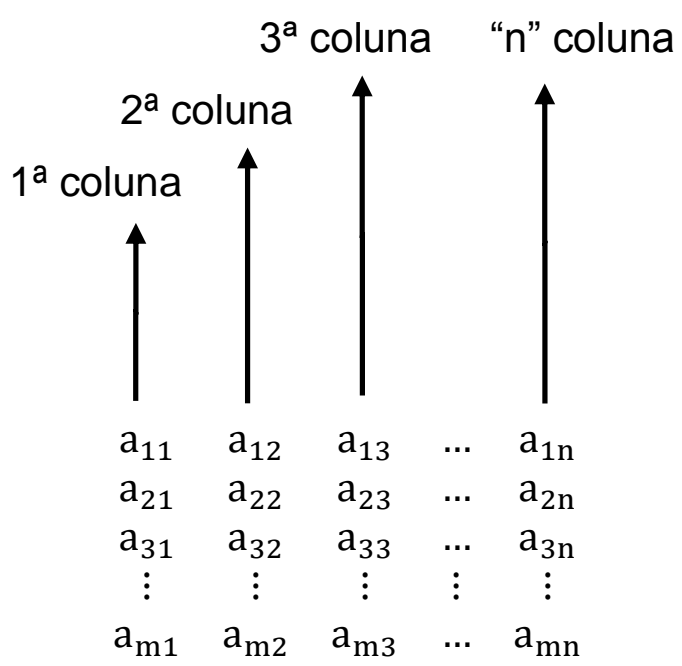

Neste sentido, foram apresentados alguns exemplos aos alunos para a familiarização com esta nova representação. Como encontrar a posição de cada elemento descrevendo em que linha e coluna se encontram: 
$A_{2 \times 2}=\left(\begin{array}{rr}5 & -2 \\ 3 & 9\end{array}\right)$, neste exemplo temos:

O elemento 5 posicionado na $1^{\underline{a}}$ linha e $1^{\underline{a}}$ coluna, logo podemos considerar $a_{11}=5$

O elemento -2 posicionado na $1^{\underline{a}}$ linha e $2^{\text {a }}$ coluna, logo podemos considerar $\mathrm{a}_{12}=-2$

O elemento 3 posicionado na $2^{\mathrm{a}}$ linha e $1^{\mathrm{a}}$ coluna, logo podemos considerar $\mathrm{a}_{21}=3$

O elemento 9 posicionado na $2^{\mathrm{a}}$ linha e $2^{\mathrm{a}}$ coluna, logo podemos considerar $\mathrm{a}_{22}=9$

Neste momento, com a empolgação dos alunos, tendo em vista que os passos 1 e 2 de Polya (2006) estavam sendo executados, explorei o ambiente da sala de aula para a discussão dos passos 3 e 4 . Para tanto, enumerei posições dos alunos nas filas das carteiras e juntos, elaboramos alguns problemas interessantes:

(I) - "Aleson": Se Thiago está na última cadeira temos 5 alunos a sua frente, considerando a sua fila como uma matriz $6 \times 1$, temos que Thiago seria qual elemento da matriz algébrica?

(II) - "Andréia": Um aluno sentado em sua cadeira sozinho, representa uma matriz 1 × 1, então que elemento da matriz genérica ele seria?

Nestes dois exemplos, foi dado um tempo para os alunos pensarem nas respostas para compreensão do problema formulado (passo 1). Algumas indagações pertinentes foram emergindo e posteriormente os alunos elaboravam planos de ação (passo 2): 
- "Mayk": "seria bom escrever as matrizes no caderno para depois determinar a solução, pois podemos lembrar de mais algum fato importante!.

Aproveitei o comentário feito por "Mayk", indaguei aos alunos utilizando a heurística proposta por Polya (2006, p.41): "conhece um problema correlato?", onde se incita o estudante a recordar um fato ou problema anteriormente resolvido, aproveitando seus dados para solucionar um novo problema:

-"Professor": "pense nos problemas já solucionados, como a matriz algébrica apresentada no quadro foi muito grande, pense num problema menor que já tenha solucionado antes, pense nos caminhos tomados e nos dados utilizados".

-“João": "Acho que basta comparar com a primeira coluna da matriz genérica que o professor copiou no quadro e teríamos já uma base para solucionar o primeiro problema!"

-“Aldemar": "No segundo problema, se a matriz $1 \times 1$ só tem um elemento só pode ser o $a_{11}$, não é professor?"

-"Maria": "isso mesmo, pois se é $1 \times 1$ ele está na primeira linha e primeira coluna, então é o $a_{11}$ tenho certeza!"

Notando o êxito dos alunos em solucionar o problema (II), formei equipes para executar um plano (passo 3) e solucionar o problema (I). No envolto das discussões traçaram alguns esquemas, ao que parece adotaram a estratégia descrita por "João": 




FIGURA 1 - Resolução dos Alunos FONTE: Próprio autor

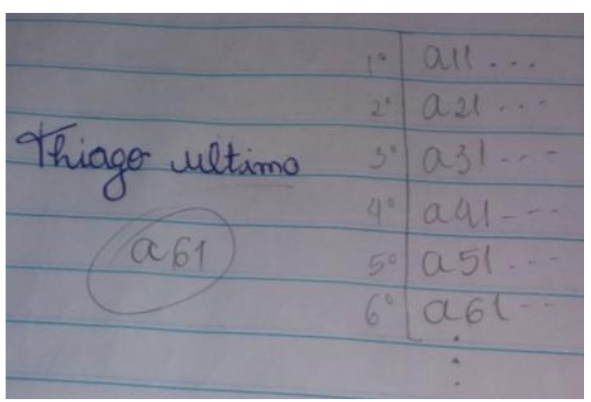

FIGURA 2- Resolução dos Alunos FONTE: Próprio auto

$\mathrm{Na}$ análise da resolução dos alunos, fizemos o retrospecto das resoluções (passo 4), observei que na primeira figura, houve um equívoco ao comparar a posição de "Thiago" com a matriz genérica apresentada. Os alunos não levaram em consideração a condicionante: "Thiago é o último da fila", sendo assim ele seria o último elemento da matriz genérica, ou seja, a61.

Já na segunda figura, temos a condicionante em primeira instância, não gerando confusão na comparação entre os elementos da matriz genérica e a posição de Thiago na fila. Demonstrando a importância de mais uma heurística proposta por Polya (2006): "qual é a condicionante?".

O método de questionar do professor, introduzindo sugestões, é imprescindível para que possa ser desenvolvida a capacidade de raciocinar diante de um problema e não somente de aplicar uma técnica específica, (POLYA, 2006, p.17).

Segundo Momento: Atividade Virtual: Representação de Matrizes:

Segundo Leblanc, Proudfit e Putt (1997, p.152), explorar os vocabulários matemáticos é importante, pois facilita a comunicação entre os envolvidos, acreditando que os termos matemáticos não devem ser evitados e sim trabalhados de modo que fiquem claros aos alunos os conceitos matemáticos envolvidos. 
Assim, como primeira atividade no grupo virtual Whatsapp, aproveitando a visão dos alunos em relacionar algo do cotidiano com a forma de linhas e colunas de uma matriz, foi postado a seguinte atividade: "postar uma foto capturada pelo seu celular que você considere que seja uma representação de uma Matriz, informando sua forma $\mathrm{m} \times \mathrm{n}$, ou seja, m-linha e n-coluna". As respostas dos alunos foram interessantes:



FIGURA 3 - Conversa Grupo Virtual FONTE: Print screen do celular do autor

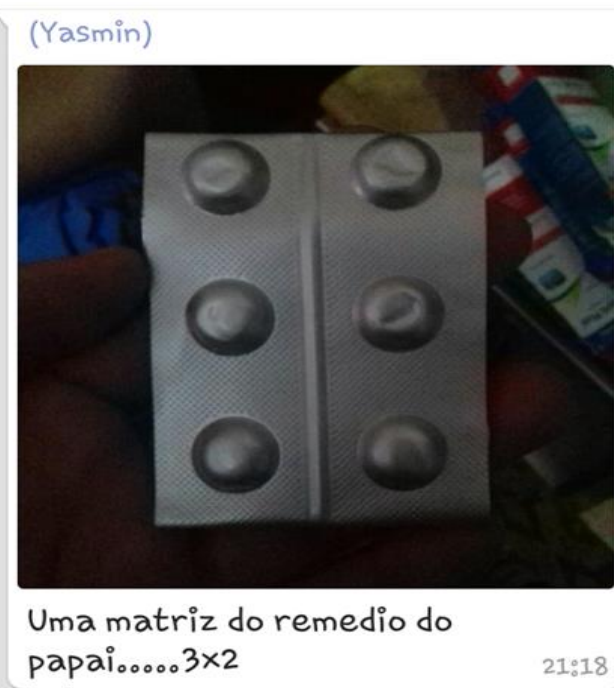

FIGURA 5 - Conversa Grupo Virtual FONTE: Print screen do celular do autor

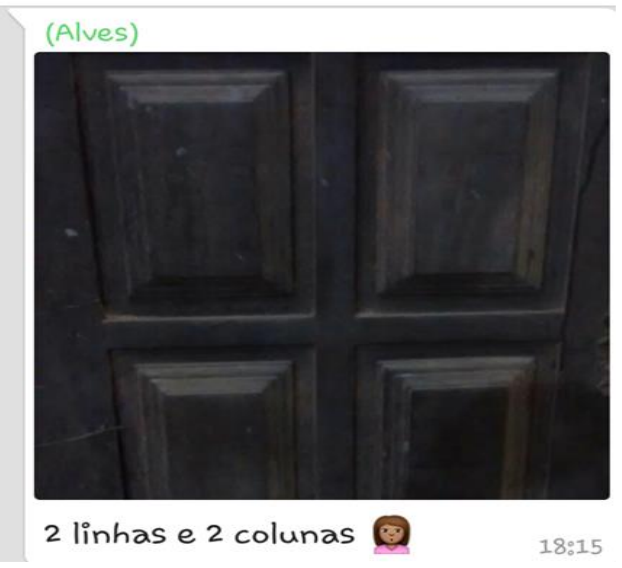

FIGURA 4 - Conversa Grupo Virtual FONTE: Print screen do celular do autor

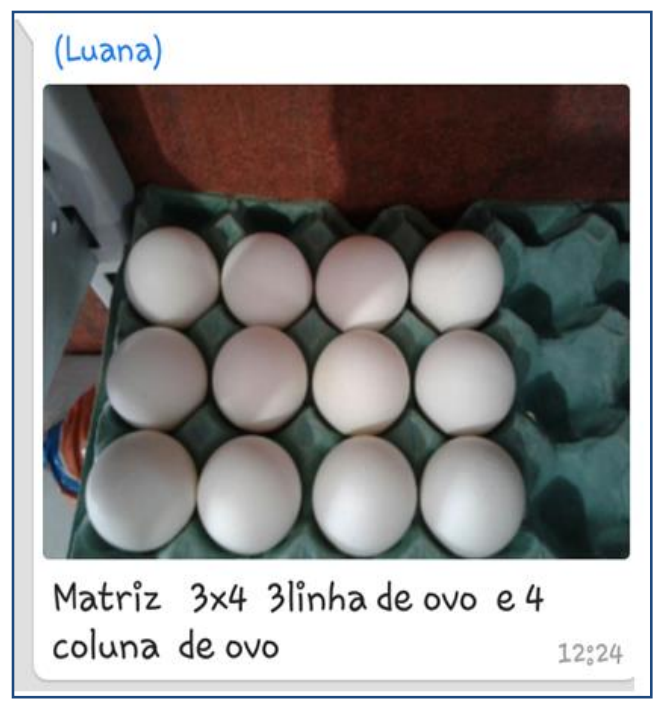

FIGURA 6 - Conversa Grupo Virtual FONTE: Print screen do celular do autor 
Considero que esta proposta estaria ligada a atividade de "reconhecimento", onde o resolvedor a realiza como forma de recordar um fato específico, uma definição (BUTTS, 1997, P.33) ou, no caso, uma definição de matriz: "matriz $\mathrm{m} \times \mathrm{n}$, toda tabela de números dispostos em $\mathrm{m}$ linhas e $\mathrm{n}$ colunas" (PAIVA, 2013, pag.95).

Esta definição parecia satisfatória para a maioria dos envolvidos na atividade proposta, porém para "Dona Lúcia" não estava tão trivial:

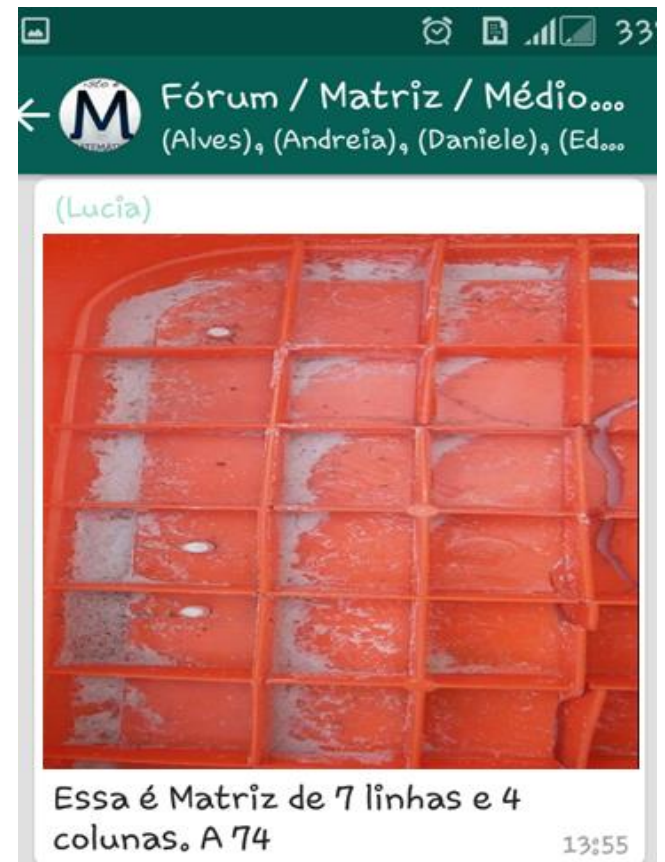

FIGURA 7 - Postagem de "Dona Lúcia" FONTE: Print screen do celular do autor

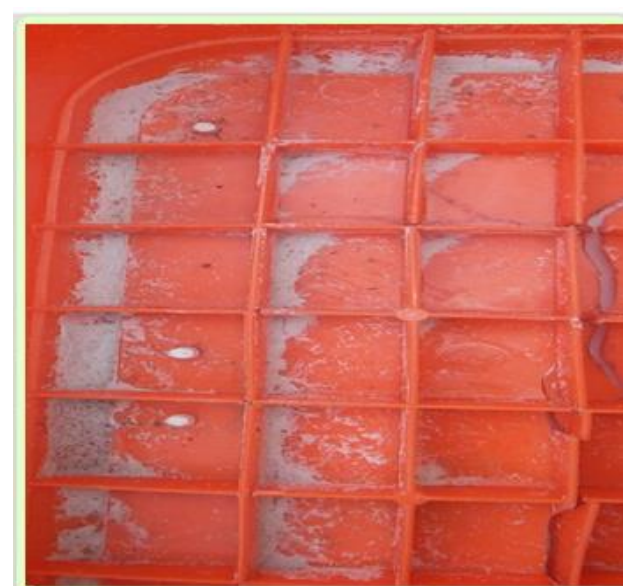

Aqui houve um erro tambem.o pois os elentos seriam os quadradinhos. . logo São 6 filas de quadrados em linha e 3 filas (ou 4) de quadrados em coluna daí matriz $6 \times 3$ (ou $6 \times 4$ ) $22: 42$

FIGURA 8 - Comentário do Professor FONTE: Print screen do celular do autor

Quando indagada sobre o equivoco, "Dona Lucia" disse que considerava como linha os espaços existentes entre os elementos na horizontal, assim como considerava coluna os espaços deixados pelos elementos na vertical. Sendo assim foi mandada uma mensagem de voz, indicando que: "o que consideramos como linha em uma matriz seria a sequência de elementos dispostos na horizontal e a coluna seria a sequência de elementos dispostos na vertical". Logo em seguida "Dona Lucia" agradeceu e postou outra imagem para ter a certeza se havia realmente entendido. 


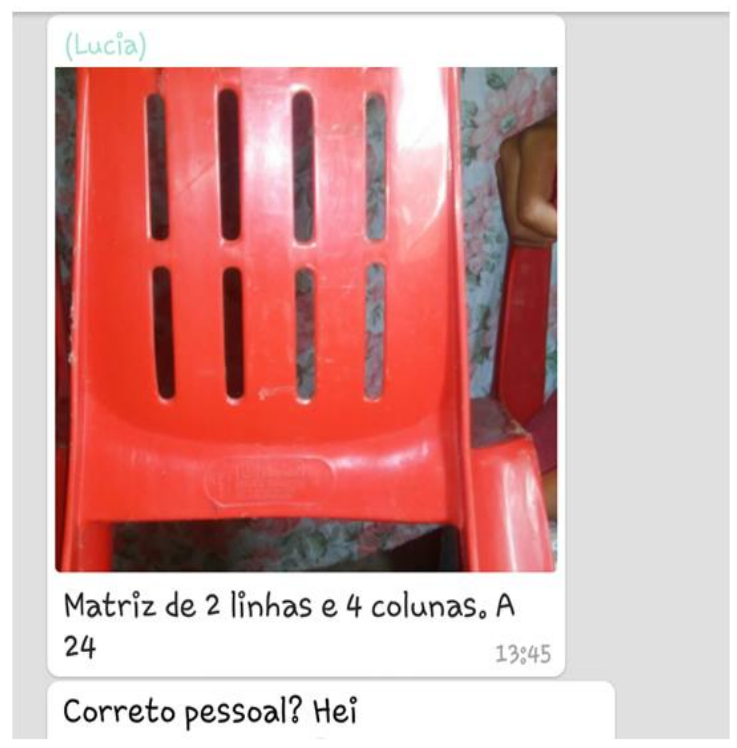

FIGURA 9 - Postagem de "Dona Lúcia" FONTE: Print screen do celular do autor

Neste momento, ficou evidente a forma como a tecnologia móvel encurta a distância entre professor e aluno, dando oportunidade de trocar ideias, mudar posicionamentos e adquirir motivação na busca por conhecimento, pois utilizar a internet para interagir, câmeras de celular para registrar momentos, molda o ambiente de estudo "criando novas dinâmicas" para trabalhar a Matemática (BORBA, 2014, P.77). Alem disso, segundo Lévy (2004, p.4), a relação entre as pessoas depende da metamorfose incessante de dispositivos informacionais, que estão cada vez mais capturando as aprendizagens.

\section{Considerações}

Incentivar o professor a trabalhar a resolução de problemas, tendo como ferramenta de apoio pedagógico a utilização do aplicativo Whatsapp, em ambientes virtuais contribuiu para a aprendizagem matemática dos alunos, pode ser um caminho que conduz à uma melhora significativa no desempenho em testes matemáticos, criando um repertório teórico para resolução de problemas, além de ter propiciado uma melhora na interação entre os envolvidos: aluno - 
aluno, professor - aluno e aluno - professor, trazendo um vocabulário matemático condizente com as turmas do ensino médio. Neste sentido, é imprescindível que o professor apresente a seus alunos problemas para serem resolvidos, pois segundo Dante (2003, p.11), a resolução de problemas ajuda o aluno a poder "pensar produtivamente", cabendo ao professor criar um ambiente de motivação e de desafio, para que os alunos queiram participar positivamente das aulas.

A proposta pedagógica apresentada no livro (produto) sugere uma reflexão a respeito da didática realizada nas aulas de matemática, assim como possíveis posturas a ser tomadas para buscar contribuir no processo formativo de profissionais docentes em exercício ou não, em um movimento em que partindo das reflexões sobre ações educativas de sua própria prática de trabalho de sala de aula, o professor poderá reorientar suas práticas, compartilhar ideias por meio do diálogo, podendo construir novos contextos, significados e sentidos às praticas e teorias aplicadas no ensino da educação básica. Pois, segundo Hartman (2015, p.13), o aprendizado reflexivo se concentra em "pensar sobre o fazer" antes, durante e depois de uma atividade de aprendizagem.

A utilização do ambiente virtual Whatsapp funcionou como elemento de promoção de atitudes positivas nos alunos, pois estes demonstraram durante a pesquisa motivação na busca de elementos para o estudo de Matrizes, participaram das resoluções de problemas frente a seus colegas sem inibições, conversarem entre si, demonstraram interesse pelo objeto de estudo em questão, além de construírem e solucionarem problemas criados por eles próprios.

O método de resolução de problemas, a mídia e as sugestões no grupo virtual serviram como ponto de interesse para os alunos interagirem, logo acredito que os professores podem utilizar o aplicativo para que os alunos possam explorar o conhecimento matemático em sua própria aprendizagem, pois a inserção da ferramenta tecnológica nas discussões dos conteúdos possibilitou ao estudante e ao professor, a socialização dos conteúdos trabalhados na prática interativa. Além disso, foi observado um alto interesse dos envolvidos nas 
atividades de resolução de problemas em sala de aula e um bom desempenho nos testes propostos.

A divisão do trabalho em dois momentos: Sala de aula (presencial) e plataforma Whatsapp, otimizou o tempo pedagógico gerando maior oportunidade de aprendizagem e um maior número de resolução de problemas matemáticos, demonstrando que o aplicativo e o modo como foi utilizado consistiu em um instrumento com um alto potencial didático para as aulas de Matemática.

Nas postagens, Surgiram muitas imagens interessantes e discussões produtivas. $\mathrm{O}$ envolvimento com a atividade proposta foi bastante proveitosa, os alunos representaram os elementos de uma matriz e a quantidade de linhas e colunas em imagens que, para eles, ficaram evidentes a existência de uma relação direta com a atividade de sala de aula.

A análise mostrou que houve crescimento dos alunos nos aspectos de interação, compreensão da resolução de problemas, ampliação dos vocabulários e repertórios dos alunos, além da superação de muitas dificuldades que apresentavam no início do trabalho de pesquisa. Logo, a descrição dessas atividades realizadas na dissertação de mestrado e explicitadas no produto da pesquisa pode servir como ponto de interesse para as aulas de matemática a professores que se identifique com a proposta apresentada.

O grupo coordenado no Whatsapp com a interação do professor e os grupos isolados com a interação somente dos alunos, constituíram verdadeiros locais discursivos, pois neles os alunos encontraram suporte para realizar suas atividades escolares, aumentando seu repertório educacional e estimulando o estudo do conteúdo de Matrizes. De forma pedagógica o uso do aplicativo Whatsapp funcionou de maneira bem sucedida em momentos fora da sala de aula, no envio de mensagens, imagens e resolução de problemas em grupo, enfim uma troca ativa de conhecimentos e informações pertinentes ao estudo do objeto matemático em questão.

Acreditamos que a proposta pedagógica apresentada no livro serve como fonte de pesquisa para futuros professores que queiram inserir a tecnologia em 
suas atividades, assim como o método de Resolução de Problemas. Servindo de exemplo para futuros pesquisadores que queiram fazer pesquisa sobre sua própria prática de sala de aula. E ainda, que os professores da EJA, não tenham medo de inovar no ensino dos conteúdos matemáticos, proporcionando uma melhor compreensão por meio da reflexão das atividades propostas, ocasionando assim um melhor aprendizado a seus alunos.

\section{Referências}

BORBA, M. C. Fases das tecnologias digitais em Educação Matemática: sala de aula e internet em movimento. 1 ed. Belo Horizonte: Autêntica Editora, 2014.

BUTTS, T. Formulando problemas adequadamente. In: KRULIK, S.; REYS, R. E. (Org.): A resolução de problemas na matemática escolar. Trad. Hygino H. Domingues e Olga Corbo. São Paulo: Atual, 1997, 343p., p. 32 - 48.

CRESWELL, John W. Investigação Qualitativa e Projeto de Pesquisa: escolhendo entre cinco abordagens. $3^{\underline{a}}$ ed. Porto Alegre: Penso, 2014.

DANTE, L. R. Didática da resolução de problemas de matemática: 1ํ a $5^{\circ}$ séries, para estudantes do curso de magistério e professores do 10 grau. 12.ed. São Paulo: Ática, 2003.

D'AMBROSIO, Ubiratan. Da realidade à ação: reflexões sobre educação e matemática. Campinas, SP: Ed. da UNICAMP; São Paulo: Summus, 1986.

GOMES, Suzana dos Santos. Infância e tecnologias. In: COSCARELLI, Carla Viana (Org.). Tecnologias para aprender. 1. ed. São Paulo: Parábola, 2016. p.143-158.

Guia do Usuário: Como Começar. Guia do Whatsapp, 2017. Disponível em: $<$ https://www.whatsapp.com/faq/pt_br/general/21073018>. Acesso em: 08 de maio de 2017.

HARTMAN, H. J. Como ser um professor reflexivo em todas as áreas do conhecimento. Porto Alegre: AMGH, 2015.

LEITE, Lúcia Helena Alvarez. Escola, cultura juvenil e alfabetização: lições de uma experiência. In: SOARES, Leôncio; GIOVANETTI, Maria Amélia; GOMES, Nilma Lino (Org.). diálogos na educação de jovens e adultos. 4. ed. Belo Horizonte: Autêntica, 2011. p. 205-224. 
LÉVY, Pierre. - As tecnologias da Inteligência- $O$ futuro do pensamento na era da informática. São Paulo: Editora 34, 2004, 13a. Edição.

LÉVY, Pierre. Cibercultura.São Paulo: Editora 34, 1999.

MENDES, I. A. Matemática e investigação em sala de aula: tecendo redes cognitivas na aprendizagem- Ed. Ver. E aum. - São Paulo: Editora Livraria da Física, 2009.

ONUCHIC, L. R.; ALLEVATO, N. S. G. Pesquisa em resolução de problemas: caminhos avanços e novas perspectivas. Bolema, Rio Claro (SP), v. 25, n. 41, p. 73-98, dez. 2011.

PAIS, L. C. Didática da Matemática; Uma Análise da Influência Francesa - 3. ed. - Belo Horizonte: Autêntica, 2001.

PAIVA, M. Matemática paiva. 2 ed. - São Paulo: Moderna, 2013

POLYA, G. A arte de resolver problemas: Um novo aspecto do método matemático. Tradução e adaptação Heitor Lisboa de Araújo. Rio de Janeiro: Interciência, 2006.

POZO, Juan Ignacio, organizador, A Solução de Problemas - aprender a resolver, resolver para aprender. Porto Alegre: ArtMed, 1998.

REIS, M. S. R. Resolução de problemas por matrizes: um caso do uso do Whatsapp na EJA do ensino médio. 2016. 96 f. Dissertação (Mestrado em Educação em Ciências e Matemáticas)-Faculdades Federal do Pará - UFPA, Pará, 2016.

SCHOENFELD, A. H. (1985). Mathematical problem solving. New York, NY: Academic Press.

SMOLE, K. S.. DINIZ, M. I. Ler, escrever e resolver problemas: habilidades básicas para aprender matemática. Porto Alegre: Artmed Editora, 2001.

YIN, Robert K. Estudo de caso: planejamento e métodos. Trad. de Cristhian Matheus Herrera. 5ํㅡㄹ ed. Porto Alegre: Bookman, 2015. 